\title{
The effect analysis of the morphing concept on the small swept flying wings
}

\author{
Vasile Prisacariu ${ }^{1, *}$, Mircea Boşcoianu ${ }^{1}$, and Ionică Cîrciu ${ }^{1}$ \\ 1 "Henri Coandă" Air Force Academy, Braşov, Romania
}

\begin{abstract}
The UAV manoeuvrability when classical control surfaces are used is limited. At present, the research focuses on the biological implications regarding total, partial or local morphing changes which might enable better trajectory control. The current paper shows an application of the flying wings with elements of twist morphing at plane edges meant to reveal a global optimum area of turning features, by use of theoretical and numerical methods.
\end{abstract}

\section{Introduction}

According to [1-2], UAVs are aerial vehicles with no pilot aboard which use aerodynamic forces for movement along 3D non ballistic trajectories, either controlled or independently, and which carry loads important to the areas of operational interest. The UAVs are largely used both in civilian and operational theatre missions. The use of this type of aerial system is cost-effective in terms of design, construction, and exploitation as compared to other manned aerial vehicles, [20].

The classical "aileron" [7] placed on the leading wing edge of the wing tips for ensuring the rolling motion was patented by the British Mattew Piers Watt Boulton in 1868. Later on, in 1906, in the USA, the Wright brothers were awarded an extended patent, (US 821393). Therefore, the geometry of the flying wing UAV is advantageous in terms of mass balance versus overall size, in the case of the same missions performed by conventional design UAVs (see Figure 1), [19].
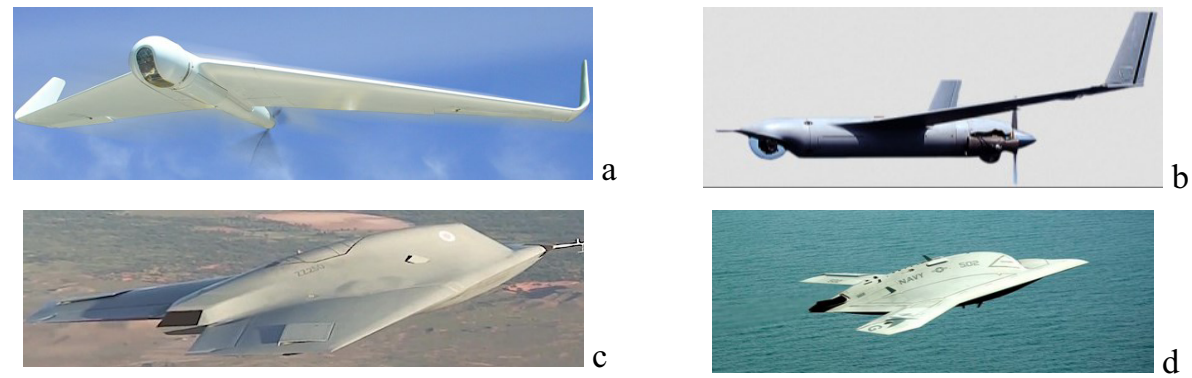

Fig. 1. Flying wing UAV (a. Orbiter-Israel, b.EagleScan-USA, c. Taranis-France. d. X46-USA), [22-25].

*Corresponding author: aerosavelli73@yahoo.com 
Wing flying compared with classical configuration offers the following advantages: lower charging that involves a higher payload; a lower total resistance to progress due to absence tail and fuselage (with their interference) witch implies an increase aerodynamic characteristics $\left(\mathrm{C}_{\mathrm{z}} / \mathrm{C}_{\mathrm{x}}, \mathrm{V}_{\mathrm{min}}\right)$; portability and modularity feature improved.

The classical control (incidence, skidding, and side slope) by turning the corresponding control surfaces (elevators, rudder, and ailerons) generates pitching movements, yaw and roll. Through turning these control surfaces can be done after the controls all six degrees of freedom of movement. The ability to change the angular velocity and flight speed (manoeuvrability) when classical control surfaces are used is limited. At present, the research focuses on the biological implications regarding total, partial or local morphing changes which might enable better control along the trajectory (see Figure 2).
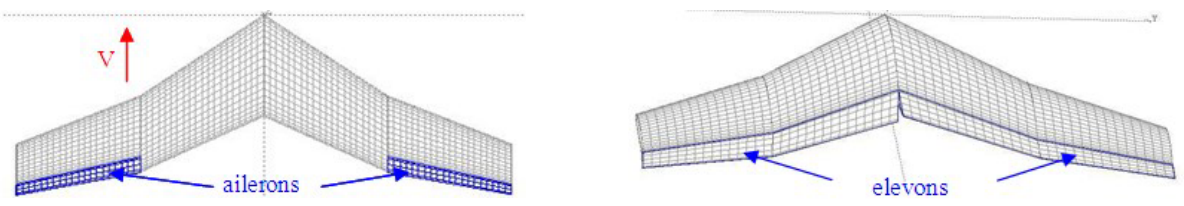

Fig. 2. Ailerons / elevons -flying wing.

Recent approaches to manoeuvrability aimed at applying the innovative morphing concepts [3-6, 12-13, 21] through replacement of classical ailerons with flexible geometries, be it local or on the surface. Manoeuvre control on the trajectory has required research, according to a series of aerial factors, of the concept of morphing which is classified as follows: 2D morphing (lift surface deformation) by means of variable geometry profiles (bending and thickness), the telescopic wing (simultaneously and alternatively), the variable-sweep wing; 3D morphing with variable-twist wing, morphing winglets (morphlets); morphing combined with the blow of the boundary layer with Coanda effect; total morphing or a combination of these (see Figure 3) [8]. The most important aspects when designing elevons are: effectiveness at low speeds and small deviations, effectiveness at high speeds and small deviations, reasonable action forces in the entire flight envelope, for reduced energy consumption.
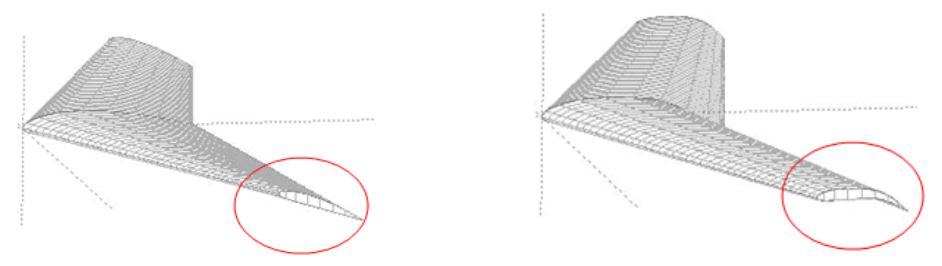

Fig. 3. Morphing concepts (twist and bending).

The application proposed is related to the flying wings ( $2 \mathrm{~m}$ wing span) with elements of twist morphing at plane edges for revealing a global optimum area of turning features, by use of theoretical, numerical, and experimental methods.

In contrast by Peter Ifju studies at Florida University [14, 15] made on the flexible wings of small and medium aspect ratio we used to study the medium aspect ratio of the semi-rigid wings. For achieve higher performance $\left(\mathrm{C}_{\mathrm{z} \alpha}\right.$ and $\left.\mathrm{C}_{\mathrm{Xi}}\right)$ so a better drag-lift ratio in a incidence range of interest. This wing falling within miniUAV class that offers advantages of portability, scalability (by extending bearing surfaces extreme easy to install depending on the specific mission). The introduction of morphing considers an increase of manoeuvrability in the average aspect ratio simultaneously with a reduction of energy use on the actuators in the use of innovative materials. The morphing advantages solution exists 
in the border areas spoiler/aileron-wing (the shear zones), see Figure 4 where this class of UAVs significant losses occur.

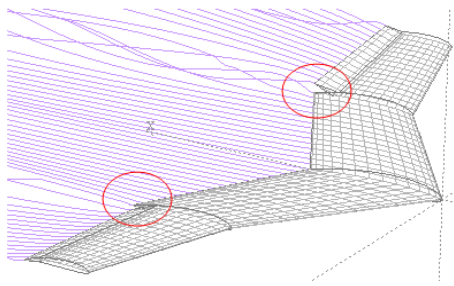

Fig. 4. The border areas spoiler/aileron-wing.

\section{Simplified analytical approach}

Proposes a simplified approach provides an analytical overview of the correlation aerodynamic elements, analytical approach that is intended as a filter so that possible solutions in the following section present an analysis of aerodynamic $3 \mathrm{D}$.

The simplified analytical approach offers better understanding of the influence of basic geometric parameters of the wing on the aerodynamic characteristics. The general conclusions are extremely relevant to the applications in the field of the morphing wing concept (significant twist and variable rigidity of the wing tip structures). Dimensioning of the control surfaces of a flying wing according to the morphing concept consists in considering a morphing surface of elevon type capable of generating rotation around the centre of gravity in order to perform 3D flight. For this we take a trapezoidal morphing surface as in the figure bellow.

$$
C_{y}=C_{0}+y \cdot\left(\operatorname{tg} \beta_{F}-\operatorname{tg} \beta_{A}\right)
$$

-we assume the linear variation $\alpha_{\mathrm{y}}=\alpha_{\mathrm{y}}\left(\mathrm{C}_{\mathrm{y}}\right)$, see Figure 6 .

$$
\alpha_{y}=\alpha_{e} \cdot \frac{C_{0}-C_{y}}{C_{0}-C_{e}}
$$

where $\alpha_{e}$ - the morphing control angle. For determining lifting (see Figure 6), we have:

$$
\begin{gathered}
d F_{z}^{\alpha}=\frac{\rho \cdot V_{\infty}^{2}}{2} \cdot c_{z}(\alpha) \cdot d S \\
d S=C(y) \cdot d y \\
d F_{z}\left(\alpha_{y}\right)=\frac{\rho \cdot V_{\infty}^{2}}{2} \cdot C(y) \cdot d(y) \cdot c_{z}\left(\alpha_{y}\right)
\end{gathered}
$$

Fig. 5. Variation $\mathrm{C}_{\mathrm{z}^{-}} \alpha$. 


$$
F_{z_{M}}=\int_{0}^{b_{M}} \frac{\rho \cdot V_{\infty}^{2}}{2} \cdot C(y) \cdot c_{z}(y) \cdot d(y)
$$

-estimating the coefficient $c_{z}(y)$, from Figure 5 we have:

$$
\frac{\alpha_{y}}{\alpha_{e}}=\frac{c_{z}(y)-c_{z 0}}{c_{z e}-c_{z 0}}
$$

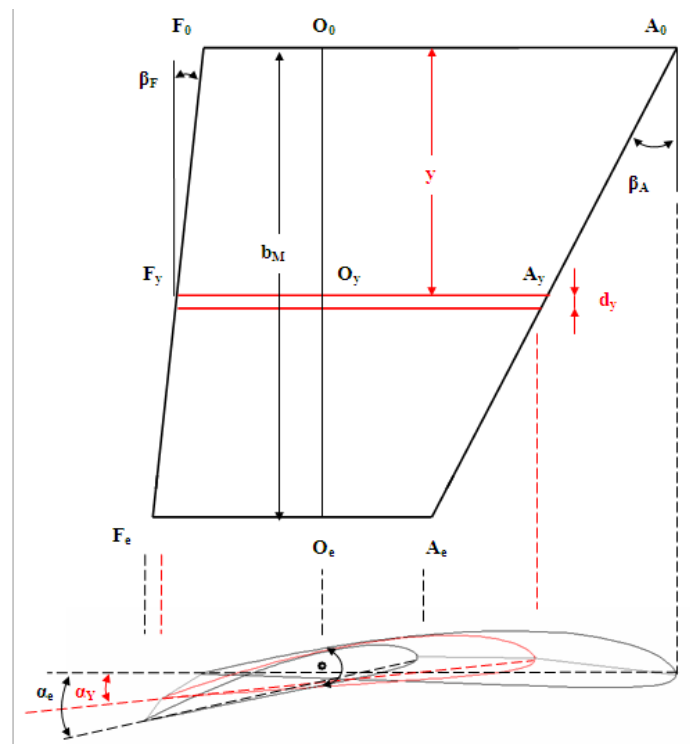

Fig. 6. Calculation of morphing parameters.

From where we obtain:

$$
c_{z}(y)=c_{z 0}+\frac{\alpha(y)}{\alpha_{e}}\left(c_{z e}-c_{z 0}\right)
$$

For calculating $\mathrm{c}_{\mathrm{z}}(\mathrm{y})$, we replace equation 1 in equation in 3 , and we have:

$$
\begin{array}{r}
\alpha_{y}=\alpha_{e} \cdot \frac{C_{0}-C_{0}-y \cdot\left(\operatorname{tg} \beta_{F}-\operatorname{tg} \beta_{A}\right)}{C_{0}-C_{e}} \\
\alpha(y)=\alpha_{e} \cdot y \cdot \frac{\operatorname{tg} \beta_{A}-\operatorname{tg} \beta_{F}}{C_{0}-C_{e}}
\end{array}
$$

-we put equation 8 in equation 10 and we get:

$$
c_{z}(y)=c_{z 0}+y \cdot \frac{\left(\operatorname{tg} \beta_{A}-\operatorname{tg} \beta_{F}\right)}{C_{0}-C_{e}} \cdot\left(c_{z e}-c_{z 0}\right)
$$

-for calculating the integral on the morphing surface, we have:

$$
F_{z M}=\int_{0}^{b M} \frac{\rho \cdot V_{\infty}^{2}}{2} \cdot C(y) \cdot c_{z}(y) \cdot d(y)
$$


-and after integration:

$$
F_{z M}=\frac{\rho \cdot V_{\infty}^{2}}{2} \cdot\left\{C_{0} \cdot c_{z 0} \cdot b_{M}+k_{a} \cdot\left[c_{z 0}-\frac{C_{0} \cdot k_{0}}{k_{c}}\right] \cdot \frac{b_{M}^{2}}{2}-\frac{k_{a}^{2} \cdot b_{M}^{3}}{3}\right\}
$$

Where:

$k_{a}=\operatorname{tg} \beta_{F}-\operatorname{tg} \beta_{A}$

$k_{c}=C_{0}-C_{e}$

$k_{0}=c_{z e}-c_{z 0}$

The control force on the lift surface is:

$$
\Delta F_{z}=F_{z M}-F_{z 0}, \quad F_{z 0}=\frac{\rho \cdot V_{\infty}^{2}}{2} \cdot S \cdot c_{z 0}
$$

So the equation 13 the morphing surface lift force depends on directly proportional to the surface the morphing $\left(\mathrm{C}_{0} * \mathrm{~b}_{\mathrm{M}}\right)$ and inversely proportional to the difference $\left(\mathrm{k}_{\mathrm{c}}\right)$ chord the morphing surface $\left(\mathrm{C}_{0}-\mathrm{C}_{\mathrm{e}}\right)$.

\section{CFD-3D analysis of the aerodynamic performance}

We propose for analysis the flying wing in figure 4 having the characteristics in table 1 .

The simulation was based on the use of a quantization network (about 6 million cells) with maximum density, as well as the effective use of the calculation resources available (CPU 2,4 GHz, RAM $24 \mathrm{Mb}$ ). The objective of the CFD analysis is to reveal the aerodynamic behaviour of the lifting surface of the flying wing type (see Figure 7 and the characteristics in table 1) in response to a set of angles of incidence.

Table1. Geometrical characteristics.

\begin{tabular}{|c|c|c|c|}
\hline Span & $\mathbf{2 0 0 0} \mathbf{~ m m}$ & Area & $\mathbf{0 , 6 6} \mathbf{~ m}^{\mathbf{2}}$ \\
\hline Profile & Clark Y & Aspect ratio & 6,67 \\
\hline Angle of sweepback for c/4 & $25^{0}$ & & \\
\hline
\end{tabular}

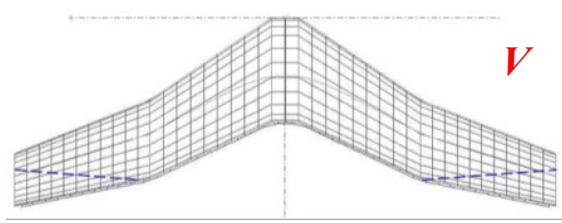

Fig. 7 Flying wing subject to CFD analysis.

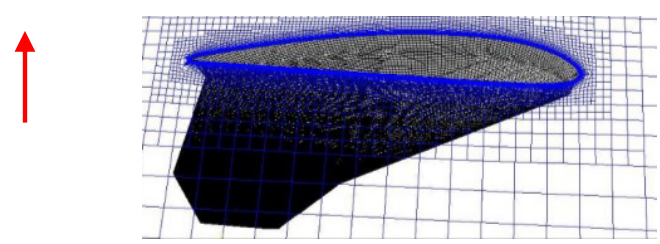

Fig. 8 Lifting surface - structured network.

The 3D numerical simulations have been achieved with the help of the Fluent solver of ANSYS 14 package by means of the method of finite elements, for investigating the aerodynamic behaviour of the lifting surface. The geometry used within CFD simulation was created so that it would be similar to models on scale 1:1. For the study of the flow, an unstructured grid has been used. The grid was in accordance with the parameters in table 2 (see Figure 8), [9, 10].

Table 2. Input parameters.

\begin{tabular}{|c|c|c|c|}
\hline Speed & $\mathbf{1 0} \mathbf{~ m} / \mathbf{s}$ & Model & Turbulent SST K- $\omega$ \\
\hline Version/method & 3D double precision & Turbulence & $4,99 \%$ \\
\hline Iterations / elements & $1000 / 6,12$ million & & \\
\hline
\end{tabular}


The aerodynamic behaviour of the chosen geometry (based on the simplified approach) can be observed with the help of the distribution of the pressure coefficient depending on the chord $\left(C_{p}-c\right)$, along five reference sections (see figure 9).

- y-coordinate-0 $0^{-35}$-extrados y-coordinate-0 0 -extrados y-coordinate-0 y-coordinate- 0 - 5 -extrado y-coordinate-1.
v-coordinate-1
0 -extrados

y-coordinate-0.1-intrados $y$-coordinate-0.35-intrados y-coordinate-0.6-intrados y-coordinate- 0.85 -intrados v-coordinate-0 1-extrados
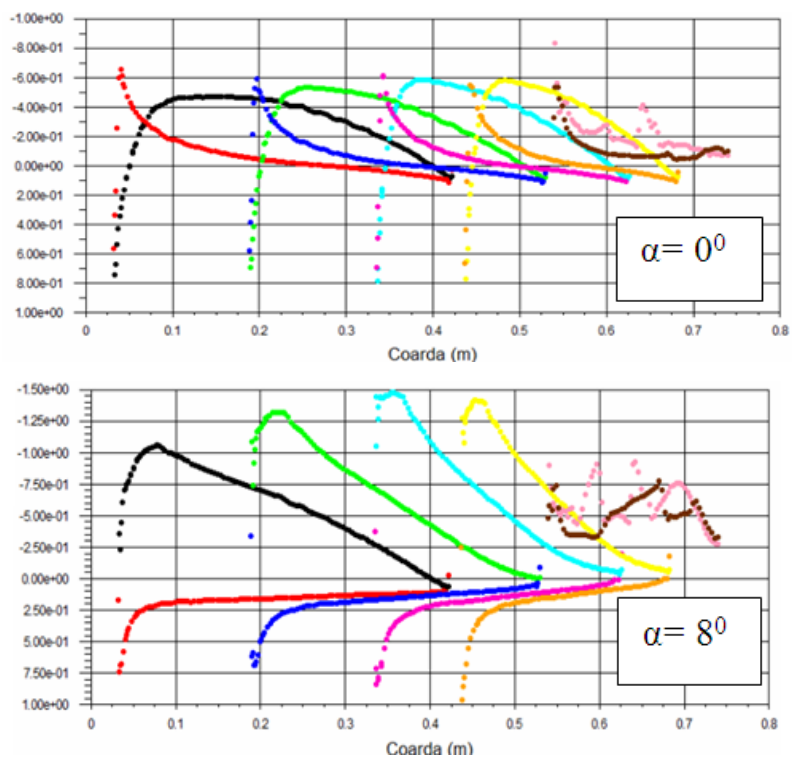

Fig. 9. Diagrams of the pressure coefficient $C_{p}$.

Table 3. Aerodynamic characteristics of flying wing.

\begin{tabular}{|c|c|c|c|}
\hline $\mathbf{A o A}$ & $\mathbf{C}_{\mathbf{z}}$ & $\mathbf{C}_{\mathbf{x}}$ & $\mathbf{C}_{\boldsymbol{z}} / \mathbf{C}_{\mathbf{x}}$ \\
\hline-40 & -0.046 & 0.020 & - \\
\hline 00 & 0.243 & 0.023 & 13.500 \\
\hline 40 & 0.536 & 0.029 & 18.483 \\
\hline 80 & 0.778 & 0.050 & 15.560 \\
\hline 120 & 0.867 & 0.113 & 7.673 \\
\hline 160 & 0.688 & 0.119 & 5.782 \\
\hline
\end{tabular}

The diagrams of $C_{p}$ (Figure 10) show the increased turbulent behaviour regarding the flow at the tip of the wing along with the increase of the angle of incidence (see Figure 10 at $\alpha=4^{0}$ and $\alpha=4^{0}$ ). A maximum of $C_{z}$ can be realized when the angle of incidence is of around $12^{0}$, (Fig. 10).
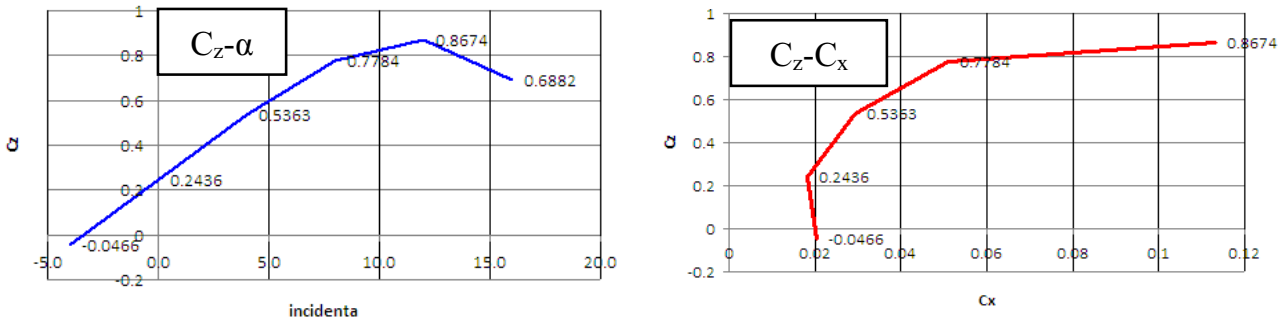

Fig. 10. Polar diagram of the flying wing.

The main aerodynamic characteristics are highlighted in Figure 10 and table 3. CFD analysis at an incidence of $12^{0}$ reveals the tendency of detachment of the boundary layers 
on the leading wing edge and on the wing tips when performing at an incidence of over $8^{0}$ (see Figure 10 and 11) and having the coefficients in table 3. It can be noticed that at $16^{0}$ the aerodynamic performance does not deteriorate significantly. In order to compare the results of the CFD analysis, we have used some free software: XFLR5 6.09 [11].

We introduced geometrical parameters identical to the input ones in table 4; for similar incidences, we have obtained the values of the graphs below (see Figure 11).

Table 4. Input parameters.

\begin{tabular}{|l|l|l|l|}
\hline Speed & $\mathbf{1 0 ~} \mathbf{~ m} / \mathbf{s}$ & Iterations / elements & $\mathbf{5 0 0} / \mathbf{2 4 0 0}$ \\
\hline Model & VLM 1 (horseshoe vortex) & Limit conditions & Dirichlet \\
\hline
\end{tabular}

There are differences between the values of aerodynamic coefficients especially when the angles of incidence are big, where there is detachment of the boundary layer and when the VLM (XFLR5 6.06) method is not effective anymore.

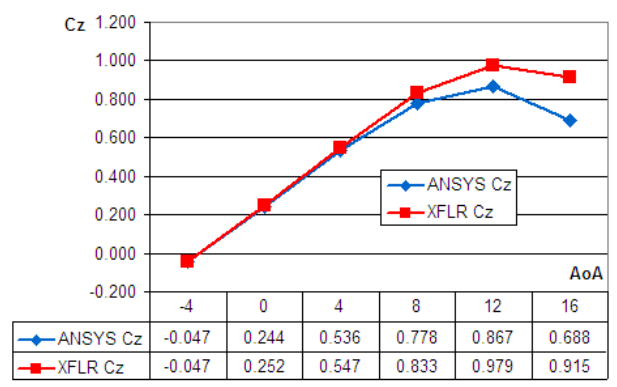

a. $\mathrm{C}_{\mathrm{z}}-\mathrm{AoA}$

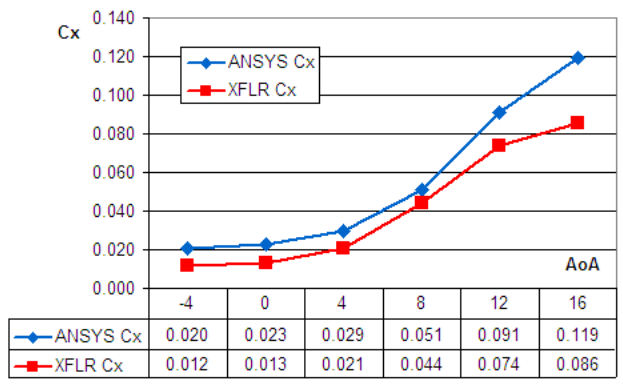

b. $\mathrm{C}_{\mathrm{x}}-\mathrm{AoA}$

Fig. 11. Comparative diagrams of the performances with focus on flight at AoA near-stall.

The graph in Figure 11a does not show significant decreases in the values $C_{z}$ critical angle which shows a post-stall behaviour acceptable. The graph in Figure $11 \mathrm{~b}$ provides an acceptable increase $\mathrm{C}_{\mathrm{x}}$ values which largely justifies the geometrical characteristics.

\section{Conclusions}

In conclusion, the results of the simulation of the flow are mainly influenced by the way network meshing is done as well as by the quality of the turbulent flow model used.

Comparing these results to the experimental data based on speed vector distribution and on Reynolds tensor distribution is also helpful. Although it is obvious that the use of the thick/light model influences the final results, we can use both types in future CFD analysis. CFD analyses by means of the VLM (vortex lattice method) provide a satisfactory degree of resolution and the results can be used in the phase preceding the project, more precisely in establishing the aerodynamic architecture, because they offer a quick image of the factors of influence. For detailed design, 3D CFD analysis, with high degrees of resolution, are recommended, especially for the study of the flow in the area of the boundary layer.

CFD design and analysis play an important role; they contribute to shortening the periods of time awarded for design, production, and testing. CFD analysis enables an early analysis with multiple possible interventions at the expense of minimum resources, which makes the difference between an expensive model which does not rise to the expectations and an optimized one. 
The authors wish to thank "Henri Coandă" Air Force Academy of Braşov and INCAS Bucureşti for supporting the research necessary for writing this article. This work is supported by the Executive Agency for Higher Education, Research, Development and Innovation Funding (UEFISCDI) under MASIM project (PN-II-PT-PCCA-2013-4-1349).

\section{References}

1. OSD UAV Roadmap 2002-2027, Office of the Secretary of Defence Acquisition, Technology, \& Logistics, Air Warfare, December (2002)

2. Unmanned Aircraft System ROADMAP 2005-2030, US DoD, Washington DC, 213 (2005)

3. S. Barbarino, O. Bilgen, R.M. Ajaj, M.I. Friswell, D.J. Inman, Journal of intelligent material system and structures, 22, 823 (2011)

4. B. Beguin, C. Breitsamter, N. Adams, AIAA Journal, 50, 2588 (2012)

5. M.D. Skillen, and W.A. Crossley, Modeling and Optimization for Morphing Wing Concept Generation, (2007), Langley Research Center NASA/CR-2007-214860, http://www.sti.nasa.gov, accessed on 01.10 .2017

6. R.W. Wlezein, G.C Horner, A.R. McGowan, S.L. Padula, M.A. Scott, R.J. Silox, and J.O. Simpson, The aircraft morphing program, AIAA-98-1927 (1998)

7. ***http://www.etymonline.com/index.php?term=aileron, accessed on 22.02.2017

8. J. Valasek, Morphing aerospace vehicles and structures (A John Wiley \& Sons, Ltd., Publication, 2012)

9. S. Dănăilă, C. Berbente, Metode numerice în dinamica fluidelor (Editura Academiei Române, $362,2003)$

10. ANSYS FLUENT User's Guide, 14, 2948 (2011)

11. M. Drela, H. Yungren, Guidelines for XFLR5 v6.03, (2011), http://sourceforge.net /projects/xflr5/files, accessed: 22.02.2017

12. V. Prisacariu, M. Boşcoianu, I. Cîrciu, C-G. Rău, Advanced Materials Research, 463, 1564 (2012)

13. M. Boşcoianu, V. Prisacariu, I. Cîrciu, A. Luchian, C. Ciufudean, Latest Trends in Applied and Theoretical Mechanics WSEAS Conference, Salerno, Italy, 9 (2014)

14. P.G. Ifju, D.A. Jenkins, and others, Flexible wing based micro air vehicles, American Institute of Aeronautics and Astronautics (AIAA), 13 (2002)

15. W. Shyy, P. Ifju, D. Viieru, Applied Mechanics Reviews, 58, 283 (2005)

16. D.P. Raymer, Aircraft design: A conceptual approach (4th edition), AIAA Education series, California-USA, 840 (2006)

17. J.D. Anderson jr., Aircraft performance and design (McGraw-Hill Book-Co Singapore, 580, 1999)

18. N.V. Constantinescu, S. Găletuşe, Mecanica fluidelor şi elemente de aerodinamică (Editura Didactică şi Pedagogică, Bucureşti, 506, 1983)

19. UAS Yearbook, Unmanned aircraft systems, The Global Perspective 2011/2012, Blyenburg \& Co, Paris, 216 (2011) available www.uvs-info.com

20. R. Austin, Unmanned Aircraft Systems - UAVs design, development and deployment (Aerospace series, Wiley and Sons Ltd publication, 365, 2010)

21. V. Prisacariu, M. Boşcoianu, I. Cîrciu, Lile Ramona, Applied Mechanics and Materials, 811, 157 (2015)

22. ${ }^{* * *}$ http://www.israeli-weapons.com/weapons/aircraft/uav/orbiter/orbiter_8.jpg, accessed: 22.04.2017

23. ***http://www.boeing.co.in/resources/en-in/media/BoeingIndia/Products-and-Services/DefenseSpace-and-Security/BDS-in-India/scaneagle_headera878.png, accessed: 22.04.2017

24. ***http://www.defense-aerospace.com/dae/articles/features/Taranis_BAE.jpg, accessed: 22.04.2017

25. ***http://www.naval-technology.com/features/featureuclass-kicks-off-4647440/featureuclasskicks-off-4647440-1.html, accessed: 22.04.2017 